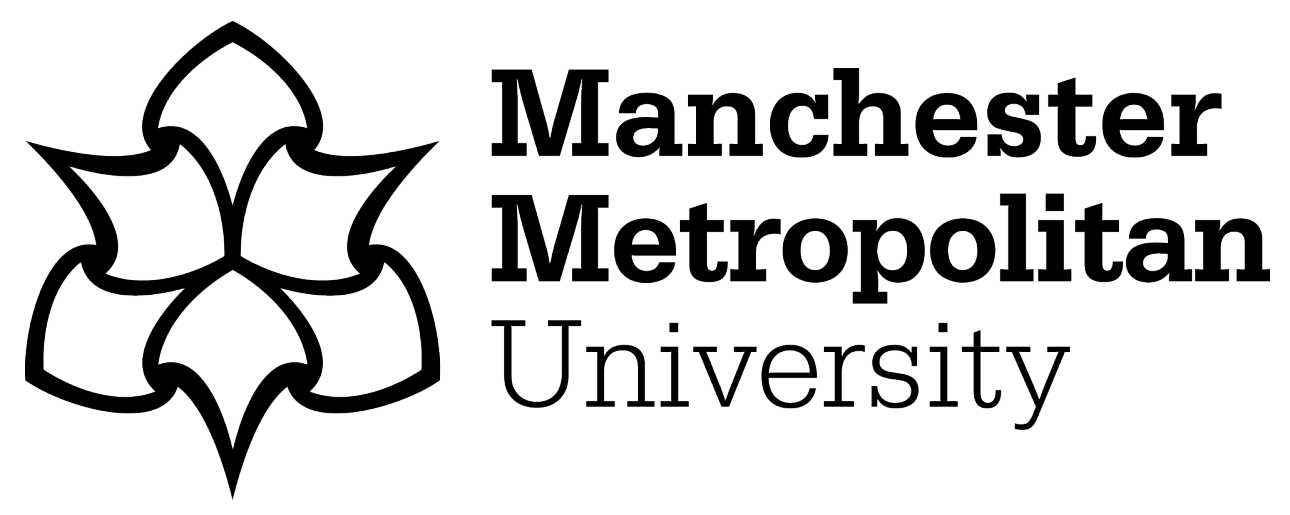

Tussyadiah, I, Jung, Timothy and tom Dieck, M (2018) Embodiment of Wearable Augmented Reality Technology in Tourism Experiences. Journal of Travel Research, 57 (5). pp. 597-611. ISSN 0047-2875

Downloaded from: https://e-space.mmu.ac.uk/618427/

Version: Accepted Version

Publisher: SAGE Publications

DOI: https://doi.org/10.1177/0047287517709090

Please cite the published version 


\title{
Embodiment of Wearable Augmented Reality Technology in Tourism Experiences
}

\author{
Authors: \\ Iis P. Tussyadiah, $\mathbf{P h D}{ }^{*}$ \\ Reader in Hospitality and Digital Experience School of Hospitality and Tourism Management \\ University of Surrey Guildford, GU2 7XH, UK Phone: +44 1483684292 Email: \\ i.tussyadiah@surrey.ac.uk

\section{Timothy Jung, PhD} \\ Director of Creative Augmented Realities Hub Department of Food and Tourism Management \\ Manchester Metropolitan University \\ C2.27 Cavendish Building, Cavendish Street Manchester, M15 6BG, UK Phone: +44 161-247- \\ 2701 Email: t.jung@mmu.ac.uk \\ and

\section{Claudia tom Dieck, PhD} \\ Department of Food and Tourism Management Manchester Metropolitan University Righton \\ Building, Cavendish Street Manchester, M15 6BG, UK \\ Phone: +44 161-247-2729 Email: c.tom-dieck@mmu.ac.uk
}

Accepted for publication in

Journal of Travel Research

April 16, 2017

\section{Acknowledgement:}

This work was supported by Knowledge Exchange Innovation Fund (No: M-80024.8.6) from Manchester Metropolitan University.

* Corresponding Author 


\title{
Embodiment of Wearable Augmented Reality Technology in Tourism Experiences
}

\begin{abstract}
The increasing use of wearable devices for tourism purposes sets the stage for a critical discussion on technological mediation in tourism experience. This paper provides a theoretical reflection on the phenomenon of embodiment relation in technological mediation and then assesses the embodiment of wearable augmented reality technology in a tourism attraction. The findings suggest that technology embodiment is a multidimensional construct consisting of ownership, location, and agency. These support the concept of technology withdrawal, where technology disappears as it becomes part of human actions, and contest the interplay of subjectivity and intentionality between humans and technology in situated experiences such as tourism. It was also found that technology embodiment affects enjoyment and enhances experience with tourism attractions.
\end{abstract}

Keywords: technology embodiment; wearable technology; augmented reality; technology mediation

\section{INTRODUCTION}

Our society today is characterized with significant advances in information and communication technologies (ICTs). These include the development of personal technologies: small, easy to carry, and relatively inexpensive computing devices designed to serve the unique informational needs of their users (Weiss, Whiteley, Treviranus, and Fels 2001), such as smartphones, tablet computers, and smart wearable devices. As many continuously embrace the latest personal devices with excitement (Consumer Electronics Association 2015) and make necessary 
adjustments to assimilate these devices into their everyday routines (ComScore 2011; Nielsen 2014; Oulasvirta, Rattenbury, Ma, and Raita 2012), ICTs become integral to everyday experiences. Recent research has emphasized the roles of ICTs in daily experiences and the spillover effects of these technology-mediated experiences to travel and tourism (e.g., Wang, Xiang, and Fesenmaier 2014a; 2014b). In fact, it is increasingly hard to decouple ICTs from tourism experiences as tourists carry and use their personal devices (e.g., smartphones) on a trip (Wang, Xiang, and Fesenmaier 2014a), affording constant connection and great computing capabilities while on the move (Tussyadiah 2015), and tourism destinations provide technological systems (e.g., mobile applications, sensors) to assist tourists in interacting with the environment around them (e.g., for information search and navigation, interpretation of cultural attractions, etc.).

More recently, the focus of personal technology development takes a new turn from designing portable devices to creating wearable computers (i.e., devices worn on human bodies), such as smart watches and smart glasses (Rauschnabel et al. 2015; tom Dieck, Jung, and Han 2016; tom Dieck, Jung, and tom Dieck 2016). The introduction of these devices to the masses implies not only that computing devices will increasingly subsume to the personal space of their users, allowing them to assist more intelligently, consistently, and continuously (Starner 2015; Starner et al. 1997), they also automatically serve as a part of users' bodily functions (e.g., gazing, sensing, perceiving) as they are embedded in the experiences and actions of their users (Ihde 1990; 1993; Gellersen 1999; Tussyadiah 2014). The use of a body-worn computer that extends users' sensory, cognitive, and motor limitations (Barfield and Caudell 2001) and adapts its behavior to the changing environments has a great implication for tourism. As tourists navigate through a tourism destination, a wearable device that is capable of extending its user's sensory 
and cognitive modality (e.g., augment views, recognize patterns) can shape how tourists orient themselves, interact, and control their interactions with tourism attractions. Additionally, as intelligent agents, wearable computers are also designed to model the behavior and predict the next actions or states of their users (Starner et al. 1997). As a result, the introduction of smart glasses through Google Glass Explorer Program (Google 2012) stimulates discussion in the literature and mass media on the potentials of wearable devices to transform touristic experiences (e.g., Dickey 2013; Prabu 2012; Tussyadiah 2014). However, it also entices fear due to its frontfacing camera that enables users to take first-person viewpoint images more surreptitiously, leading to perceived threats on personal privacy (e.g., Penn 2015).

Despite the mixed reactions to commercial smart glasses for everyday experiences, an area of relevance for the use of smart glasses in facilitating tourism experiences is augmented reality (tom Dieck, Jung, and Han 2016; tom Dieck, Jung, and tom Dieck 2016). Augmented reality is an application that supplements natural (as opposed to artificial) world with additional information, achieved by overlaying visual, auditory, or even haptic materials on physical objects presented through see-through displays (Azuma 1997; Barfield and Caudell 2001; Feiner, MacIntyre, Höllerer, and Webster 1997). An augmented reality system combines physical and virtual (artificial) objects in a natural environment, aligns these objects with each other, and runs interactively in real time (van Krevelen and Poelman 2010). By performing a seamless integration between computer-generated information and user sensation of the natural world, the ultimate goal of augmented reality is to support user interaction with the world around them (Barfield and Caudell 2001; Starner 2015; Starner et al. 1997). In the context of tourism, augmented reality is applied to assist tourists with retrieval and processing of information on points of interest (POI) in the vicinity (e.g., physical structures, historic and cultural objects, 
museum exhibits, etc.), enhance their perception and cognition processes, and aid in decision making (Kounavis, Kasimani, and Zamani 2012; Yovcheva, Buhalis, and Gatzidis 2011; Yovcheva, Buhalis, Gatzidis, and van Elzakker 2014). Augmented reality applications designed to enhance experiences outdoors have been applied in national parks, heritage sites, and recreation areas as well as tourist cities, providing augmented walking experiences for tourists (e.g., Caggianese, Neroni, and Gallo 2014; Chung, Han, and Joun 2015; Fritz, Susperregui, and Linaza 2005; Gleue and Dähne 2001; Han, Jung, and Gibson 2014; tom Dieck and Jung 2015). Additionally, indoor touristic experiences enhanced with augmented reality are developed in museums, art galleries, and indoor theme parks by overlaying exhibits with additional information through touch-screen displays, smartphones, and/or wearable devices (e.g., Damala, Marchal, and Houlier 2007; Jung, Chung, and Leue 2015; Leue, Han, and Jung 2014; Leue, Jung, and tom Dieck 2015; tom Dieck and Jung 2015; Wojciechowski, Walczak, White, and Cellary 2004). Partnering with GuidiGo (i.e., a developer of publishing platforms for guided tours) and Google (i.e., the maker of Google Glass), San Francisco's de Young Museum was among the first to introduce Google Glass-powered exhibition in 2015 (McGee, 2014). Using Google Glass, museum visitors were able to access audiovisual materials and testimonials revealing the hidden story behind Keith Haring's artworks.

The advancement in wearable computing and augmented reality and its potential impacts on tourist experiences have been emphasized from a practical point of view. However, there is void in literature as far as how the intricacies of human-computer interactions through augmented reality applications are critically situated within the discourse of tourism experience and how to better understand the implications of these interactions for tourism management. To that end, this research aims to conceptualize and assess technology mediation by analyzing the 
use of wearable augmented technology in situated tourism experiences. In particular, this research is directed towards tourists' perception on the transformed representation of attractions and their overall experiences while using wearable augmented reality technology. A better understanding on the embodiment of wearable technology will be helpful to guide the management of tourism attractions in which advanced technological systems are involved.

\section{THEORETICAL BACKGROUND}

\section{Mediation of Tourism Experience}

Mediation or brokerage mechanism exists in tourism experiences in order to bridge the self (i.e., the tourists) and the others (i.e., the destinations) (Holloway 1981; Jennings and Weiler 2006; Jensen 2010; Macdonald 2006). Macdonald (2006) distinguishes between communicative and interaction mediation supported by tour guides. While the former influences tourist understanding, the latter facilitates interactions with locals and the environment. Similarly, Weiler and $\mathrm{Yu}$ (2007) categorize mediation into three areas: physical access, cognitive access, and social access. In addition to these, McGrath (2007) suggests emotional or affective access as another domain of mediation in tourism. For example, as cultural brokers, tour guides facilitate interactions between tourists and local culture, provide translation and interpretation (i.e., communicating meaning) and, in doing so, influence tourists' cognitive and affective responses to tourism destinations. Following Turner and Ash (1975), as tourists are placed at the center of a strictly circumscribed world, Urry and Larsen (2011) argue that tourism mediators such as hotel concierges and tour guides act as surrogate parents, relieving tourists of responsibility and protecting them from harsh reality. 
Mediation in different domains of tourism experience is highly associated with provision (or withholding) of information. The development in ICTs enables technology devices and digital media to take the roles of conventional tour guides in assisting tourists with their physical, cognitive, social, and affective experiences with tourism destinations (Jansson 2012; Tussyadiah and Fesenmaier, 2009; Wang, Park, and Fesenmaier 2013). For example, tourists who use their smartphone's global positioning system (GPS) for navigation or translation app to bridge a language barrier are afforded access to physical and social experiences. Similarly, information overlay with augmented reality is an example of how technology mediates tourists' cognition and learning experience (e.g., Leue, Han, and Jung 2014; Leue, Jung, and tom Dieck 2015; Yovcheva et al. 2011; 2014). As a result, in order to explain the roles of ICTs in tourism experiences, it is appropriate to consult the (post)phenomenological approach to technological mediation (Ihde,1990), where technology stands in relation between humans (i.e., tourists) and the world around them (i.e., tourism destinations) (Tussyadiah and Fesenmaier 2009; Wang, Park and Fesenmaier 2013). Following Ihde's (1990) viewpoint on the roles of technology in society, schematic explanations of direct encounter (i.e., in terms of bodily and perception), mediation of tour guides, and technological mediation in tourism can be presented as below:

Direct Encounter: $\quad$ Tourist - Destination

Contemporary Mediation: $\quad$ Tourist - Tour Guide - Destination

Technological Mediation: Tourist - Technology - Destination

Further, Ihde (1990) describes four different types of relation that occur in technological mediation. Embodiment relation occurs when users embody technology (i.e., so it becomes an extension of human bodies), allowing the extended bodies to interact with the world. Alterity relation occurs when humans interact with technology artifacts as if they were living beings and, 
thus, social actors. The third relation, hermeneutic, is somewhat in between embodiment and alterity, where technology provides representation of reality that needs to be interpreted to generate perception about the world. Finally, technology plays a role at the background of human experiences, creating a context for their perception. The schematic explanation of Ihde's (1990) four relations in technological mediation in tourism context is presented below:

Embodiment Relation: $\quad$ [Tourist - Technology] $\rightarrow$ Destination

Hermeneutic Relation: $\quad$ Tourist $\rightarrow$ [Technology - Destination]

Alterity Relation: $\quad$ Tourist $\rightarrow$ Technology [- Destination]

Background Relation: $\quad$ Tourist [-Technology - Destination]

These relations can be explained in tourism context to a varying degree. The use of automated ticket dispensers at a train station or check-in kiosks in a hotel is a form of interaction between a tourist and another agent, which represents alterity relation. In these cases, technology is the terminus of a tourism experience (Verbeek 2007; 2008). An example of hermeneutic relation is tourists' use of weather application on a smartphone. While the app itself does not give tourists an actual experience of sun or rain, it delivers a representation (i.e., a value, a symbol) that needs to be read in order to retrieve information regarding the condition of tourism destinations. A smartphone automatically tracking users' movement and location is an example of background relation. Despite receiving limited attention in tourism literature, embodiment relation is the most relevant to the development and use of wearable personal devices for tourism. Wearable devices are not encountered as objects in tourism destinations, but the means through which tourists perceive the destinations. Therefore, embodiment relation provides a framework to contest the subject - object dualism attached to human-computer interactions in cases of situated experiences such as tourism. 
Verbeek (2007) suggests that from a modernist perspective, technology mediation only concerns with how to present objects to the subjects without affecting subjectivity and objectivity themselves (i.e., technology is neutral). However, when tourists perceive an augmented vision of a tourism attraction as a result of seeing through the Google Glass, technology does not only generate a new form of objectivity, but also of subjectivity. Thus, from a postmodernist perspective, subjects and objects do not have fixed essences; what is essential to them depends on the context and their relations with other entities. Through mediation, technology helps constitute the interpreted reality of the world and the situated subjectivity of human beings by shaping people's perception, interpretation, and forms of engagement with reality. Finally, a posthumanist perspective involves the interplay of intentionality (Ihde, 1990). According to Verbeek (2007), a posthumanist regards technology artifacts as generators of multiple realities, demonstrating artifactual intentionality that is either augmented (i.e., blending multiple visual impressions into a single representation of reality, such as in augmented reality), constructed (i.e., constructing a new reality, such as in virtual reality), or reflexive (i.e., making technological perception of human experiences perceptible to humans, such as displaying tourist movements as GPS coordinates on a map). Analyzing how wearable augmented reality technology influences tourism experiences requires moving away from a modernist approach that assumes the neutrality of technology. By focusing on embodiment relation in technology mediation, this study attempts to critically position technology with(in) the human subject in the durée of tourism experience.

In addition to the practical reason that is the potential of wearable computing devices to gain prominent roles in tourism experiences, technology embodiment is epistemologically interesting for several reasons. Brey (2000) raises a question on the nature of transformed 
experiences (i.e., mediated perception) resulting from the pre-processed, enhanced experiences through technology. Verbeek (2007) argues that augmented or constructed realities are largely a result of technology - world relation instead of human - world relation mediated by technology. This is similar to the positioning of tour guides as surrogate parents for tourists (Urry and Larsen 2011), where tourists interact with realities constructed and shaped by the mediators. In the case of wearable augmented reality, by sensing the world around it, the device produces a mechanical amplification of some aspects of human vision intentionality as tourists direct their gaze toward the natural environment (e.g., a tourism attraction). Consequently, it is important to understand how tourists perceive the representation of realities (i.e., the projected images) resulting from augmented reality experiences, which in essence is a question of authenticity.

To embody means to give a body to an agent, a person, or a system (Giraud, Paljic, and Leroy 2013). In the case of wearable devices, users are often consciously unaware of the presence of these devices after an initial habituation period. This suggests that technology embodiment engenders a symbiosis of human and technology, which implies the importance to research how users acquaint with technology that integrates with human bodies (Brey 2000). Ihde (1990) explains the situation of technology withdrawal, where technology becomes transparent means through which users perceive their natural environment. The use of Google Glass equipped with augmented reality to gaze at a tourism attraction elucidates this idea. When a tourist is used to having a head-mounted device with a screen right in front of her eyes, she becomes consciously unaware of the device's physical position as she experiences seeing through the Google Glass. Brey (2000) takes into account Merleau-Ponty's (1962) phenomenological description on the relation between the body and the external world to explain how users perceive wearable technology differently from other objects external to their bodies. 
Merleau-Ponty (1962) contrasts the space of a body (i.e., space of situation) from that of an external environment (i.e., space of position). Humans perceive their bodies by means of a body schema (Gallagher 1986; Longo and Haggard 2012), which provides a pre-reflective, immediate knowledge of the position of their body parts. Longo and Haggard (2012) refer to this perception as bodily awareness, which is a non-conceptual, somatic, form of knowledge (Longo et al. 2008). Body schema is different from body image, which is the perceived form of human bodies in terms of sizes, shapes, and distinctive characteristics (Longo, Schüür, Kammers, Tsakiris, and Haggard 2009). Therefore, human bodies are a medium through which humans engage with the world, but are not experienced as a spatial entity. Brey (2000) proposes that wearable technology is integrated into the body schema of its users and, thus, becoming a medium through which their motor and/or perceptual skills are expressed (e.g., Google Glass is the means through which tourists' visual perception takes place). Hence, wearable technology extends human bodies through enhancement of motor and/or perceptual skills (Verbeek 2015).

\section{A Psychometric Approach to Technology Embodiment}

The phenomenological tradition has provided rich descriptive characterization of embodiment (e.g., Merleau-Ponty 1962), including that of technology (e.g., Brey 2000; Ihde 1990; Verbeek 2007; 2008). However, assessing technology embodiment in actual experiences will be useful not only to support a critical reflection of the roles of technology in human experiences, but also to appraise the quality of mediated experiences. For that reason, a number of studies in neuroscience and psychology attempt to conceptualize and assess technology embodiment from a psychometric approach (e.g., Longo et al. 2008; 2009). Longo et al. (2008) suggest that embodiment is a form of experience that the traditional methods in psychology have difficulty in 
capturing its nature. Consequently, they propose a more systematic approach to rigorously define embodiment as a coherent psychological phenomenon and decompose its structure.

Longo et al. (2008; 2009) conducted an experiment with rubber hand illusion (RHI), where participants observe a rubber hand that was stroked synchronously or asynchronously (i.e., resulting in visual and haptic perception) and then respond to introspective measurements about their experience. Longo et al. (2008) identified a construct they termed embodiment of rubber hand, which consists of three subcomponents: ownership, location, and agency. Ownership represents the feeling that the rubber hand is part of one's own body. Location relates to the feeling that the rubber hand and one's own hand are located at the same place. Agency is associated with the feeling that one can control the rubber hand, being able to move it. For this research, the introspective measurements from Longo et al. (2008) were adapted to assess the embodiment of wearable augmented reality in the context of tourism attractions. Following their findings, this research assesses that technology embodiment is a multidimensional scale consisting of three subcomponents: ownership, location, and agency. It is hypothesized that ownership, location, and agency are distinct, but related constructs and accounted for by a common underlying higher order construct, namely technology embodiment of Google Glass. Hypothesis 1: Technology Embodiment is a higher order construct underlying Ownership, Location, and Agency.

While the core of this research is the assessment of technology embodiment, it is recognized that relating technology embodiment to its behavioral outcomes is important. Hence, this research attempts to assess if embodiment of wearable augmented reality has an effect on experiences with tourism attractions. From the perspective of technology development, studies assessing augmented reality applications in various contexts place enjoyment, which reflects the 
performance of embodied interactions afforded by the use of such technology, as an important factor representing user experiences (e.g., Bressler and Bodzin 2013; Macvean and Riedl 2011; Morrison et al., 2009). This is especially so when the technology is designed to serve hedonic purposes (Van der Heijden 2004), including for tourism (Caggianese, Neroni, and Gallo 2014). The basic tenet is that interacting with mixed reality (i.e., merging of real world and synthetic elements) stimulates user interest and engagement during the experience, leading to enjoyment (e.g., Macvean and Riedl 2011; Sylaiou, Mania, Karoulis, and White 2010). In areas of gaming and physical activities, it is suggested that embodiment during an activity can influence emotion and increase the experience of fun (Price, Peterson, and Harmon-Jones 2012). Therefore, this research hypothesizes that the embodiment of wearable augmented reality technology has a positive effect on tourists' enjoyment while interacting with tourism attractions. This research utilizes Davis, Bagozzi, and Warshaw's (1992) definition of perceived enjoyment, which is the extent to which the activity of using wearable augmented reality to interact with tourism attractions is enjoyable in its own right.

Hypothesis 2: Technology Embodiment has a positive effect on Enjoyment.

Additionally, tourism literature suggests the enhancement of overall tourism experience as an outcome of technology mediation (e.g., Neuhofer, Buhalis, and Ladkin 2012; Tussyadiah and Zach 2012). Specifically, previous studies on augmented reality in tourism found that the use of this technology enhances the tourist experience (e.g., Chung et al. 2015; Jung et al. 2015; Yovcheva et al. 2011; 2014). Embodiment relation in technological mediation implies the integration of technology into the user's body schema (Verbeek 2015), augmenting the body's abilities and dispositions to be actualized in everyday experiences. The body schema enables an understanding of the environment as a space of possible engagement and action, of objects ready 
to hand (Fuchs and Schlimme 2009; Stanghellini 2009). Embodying technology expands these possibilities. In tourism settings, embodiment of wearable devices enhances tourists' skills, thus expands the range of possible engagement with tourism destinations, of objects (both natural and artificial) to be seen, perceived, understood, and appreciated. As a result, the "outcome" or "consequence" of technology embodiment in tourism is reflected in the tourist's experience. This study proposes that embodiment of wearable augmented reality technology positively influences an overall experience with tourism attractions.

Hypothesis 3: Technology Embodiment has a positive effect on overall Experience.

Perceived enjoyment has been suggested as an important post-adoption factor to influence users' evaluation of their experience with hedonic information technology (Thong, Hong, and Tam 2006; Van der Heijden 2004). Indeed, research has incorporated perceived enjoyment into technology adoption models, especially in cases of continued technology usage intention (Van der Heijden 2004; Venkatesh and Brown 2001), as it contributes positively to users' satisfaction with technology usage. In tourism settings, wearable augmented reality technology is used for pleasurable experiences (e.g., sightseeing). Hence, it is expected that the post-adoption level of enjoyment (i.e., the degree to which the technology usage is considered fun or enjoyable by the users) becomes important in developing a positive evaluation towards the outcomes of using the technology. Therefore, it is hypothesized in this research that enjoyment from interacting with tourism attractions using wearable augmented reality technology contributes positively to the overall tourism experience. Hypothesis 4: Enjoyment has a positive effect on overall Experience. 


\section{METHOD}

The measurement items from Longo et al. (2008) were adjusted to the context of this research with the following considerations: (1) the experience in this research centers in different body parts (i.e., eye[s] vs. hand), (2) while participants are able to see the location of their own hand in Longo et al.'s experiment, in this research participants perceive where their eyes are from their visual sensation, and (3) Longo et al.'s experiment involves interactions with an illusion of a rubber hand (i.e., replacing own hand), thus focusing solely on human - technology relation, while this research includes computer-generated information overlay on the natural environment (i.e., enhancing visual perception when interacting with the environment), thus involving technology - world relation in perspective. Statements measuring ownership, location, and agency were rephrased to fit the context of this research. Initially, four tourism and information systems experts in the United States and five tourism experts in the United Kingdom reviewed the statements to ensure readability and consistency in terms of interpretation. Items measuring enjoyment and experience were adopted from previous studies (e.g., Igbaria, Parasuraman, and Baroudi 1996; Van der Heijen 2004; Venkatesh 2000). The final list of measurement items consists of five items measuring ownership, four measuring location, four measuring agency, three measuring enjoyment, and three measuring experience (see Appendix A for measurement items).

This study was conducted as a part of the wearable augmented reality project at an art gallery in the United Kingdom. The gallery is one of the country's finest art museums and houses important fine and decorative art works, which have been designated as being of national

importance. The gallery is renowned for the $19^{\text {th }}$ Century British paintings and attracts over half a million visitors each year. For this study, Museum Zoom Google Glass application (also called 
Glassware) was developed to enhance the visitor experience in the art gallery. The application consisted of Google Glass Cards (i.e., the Glass “screen” viewed by users) containing basic text information as well as audiovisual information (i.e., computer-generated, artificial objects), superimposed on the gallery exhibits: the paintings (i.e., natural objects). These Cards contain information on the artist, the paintings, and a menu with sharing functions (see Appendix B for examples of Museum Zoom Cards). The visitors to the gallery will embark on an augmented reality journey as they interact with the paintings and the Cards. Information about the painting were digitally overlaid into visitors' direct field of vision when viewing a painting. The visitors can see the Cards by directing the Google Glass (i.e., their gaze) to the paintings and use the touchpad or voice command to scroll through or reveal more Cards to learn about the details of the paintings. As the visitors walk through and see different paintings, they will be able to view various relevant Cards digitally overlaid onto the real painting, experiencing an augmented tour around the museum. Researchers approached every $10^{\text {th }}$ gallery visitors at the entrance and asked if they were willing to participate in the study. Once they agreed to participate, visitors were asked to experience the Museum Zoom Google Glass application and then complete the questionnaire. Considering that most visitors were not aware of Google Glass augmented reality application, participants were provided a manual to familiarize themselves with the applications. After reading the manual, visitors used the application for about 30 minutes and then participated in the survey.

The first data collection was conducted on three consecutive days in November 2014; 126 visitors participated in the study. The second data collection was conducted on two consecutive days in February 2015 with 85 participants, yielding a total of 211 responses. Participants are relatively balanced in terms of gender (53\% male) and mostly younger, with 
$56 \%$ younger than 35 years. Most participants are highly educated, with more than $60 \%$ holds at least a Bachelor's degree. In terms of income, 54\% participants indicated that they have an annual income of $\$ 32000$ or less. The comparison between respondents from first and second data collection is presented in Table 1. To be mindful of non-response bias, this research undertook two approaches. First, several $\chi^{2}$ tests were conducted in order to identify if the characteristics of respondents in Phase 1 are different from those in Phase 2 of data collection. No significant differences were found, indicating that early respondents are not different from late respondents. Additionally, secondary data on the share of adults in England who visited a museum or gallery between 2012/2013 and 2014/2015 (Statista 2016) were consulted. The data show that respondents in the youngest (below 25) and oldest (65 and above) age groups tended to have a lower rate of attendance, with those between 25 and 44 representing the highest share. The composition of respondents in this study fit the aforementioned characteristics, with a slightly larger share of young visitors. Therefore, it can be suggested that it is unlikely that this study misses a key group of gallery visitors who might respond differently to the survey and influence the findings.

\section{$==$ Insert Table 1 about Here $==$}

Data were analyzed following Anderson and Gerbing's (1988) two-step approach: (1) testing the adequacy of the measurement model with a confirmatory factor analysis (CFA), and (2) assessing the adequacy of the structural model for hypotheses testing. The analysis was performed using MPlus program (Muthén and Muthén 1998-2012). The covariance-based structural equation modeling (CB-SEM) was utilized due to the theoretical goal of this study, which is to assess the overall fit of the proposed research model. CB-SEM is capable of determining if the proposed causal model is a sufficiently "good" way to model the relationships 
among the variables, that the complete set of paths specified in the model is plausible given the sample (Gefen, Straub, and Boudreau 2000), the capability that PLS-SEM does not have (Chin 1998; Lowry and Gaskin 2014; Hair, Ringle, and Sarstedt 2011). To assess the normality of data, skewness and kurtosis values of all variables were consulted. As shown in Table 2, some variables have skewness values outside of range for normal distribution. Therefore, in order to account for the non-normality of data distribution, the analysis was performed using maximum likelihood parameter estimate with standard errors and a mean adjusted Chi-square test statistic (Satorra-Bentler corrections) that are robust to non-normality (MLM). It is also important to note that while the sample size is relatively small due to the intensive nature of data collection $(N=$ 195), it is larger than the suggested minimum of 10 cases for every indicator variables (Nunnally 1967 ) and above the range of the suggested minimum sample size of $100-150$ (Anderson and Gerbing, 1988; Ding, Velicer, and Harlow 1995; Tinsley and Tinsley, 1987). Additionally, following MacCallum, Browne, and Sugawara's (1996) power analysis, the required minimum number of observations for a close of fit was estimated using the following criteria: desired power $=90 \%$, significance level $=.05$, RMSEA $_{1}=.05$, and RMSEA $_{0}=.08$. The calculation yielded a required sample size of 128 . Several criteria were used to assess the validity and reliability as well as goodness of fit for both measurement and structural models.

$$
==\text { Insert Table } 2 \text { about Here }==
$$

\section{FINDINGS}

The results from CFA (see Table 3) show that all factor loadings are above .6, except for LO3 that is a little below $.6(\mathrm{LO} 3=.579)$. Moreover, all latent variables have average variance extracted (AVE) values above the cutoff point of .5 (Hair, Black, Babin, and Anderson 2010). 
These indicate that convergent validity was supported. The composite reliability $(C R)$ values are above the cutoff criteria of .7 (Hair et al. 2010), which indicate reliability. From Table 4, it is shown that the values of square roots of AVE (presented in the diagonal) are higher than the correlations between the corresponding variable and any other variables, supporting discriminant validity. Further, the model fit criteria are supported, with $\chi^{2} / d f$ less than $3\left(\chi^{2}=283.113, d f=\right.$ $146, p=.000)$ and fit indices (i.e., Comparative Fit Index $[C F I]=.928$ and Tucker Lewis Index $[T L I=.915)$ above the thresholds of .9 (Hu and Bentler 1999). The value of Root Mean Square Error of Approximation $(R M S E A=.069)$ indicates moderate model fit $(\mathrm{Hu}$ and Bentler 1999) and the value of Standardized Root Mean Square Residual $(S R M R=.065)$ is below the threshold of .09 (Hu and Bentler 1999). These criteria suggest the adequacy of the measurement model. Additionally, in order to test for common method bias, Harman's single factor test was performed by conducting an exploratory factor analysis with all items representing Ownership, Location, and Agency as a single factor (i.e., with the number of factor fixed to one). The results from Harman's test specifies that embodiment as a single factor explains only $45.47 \%$ of variance in the data, which is less than the cutoff point of 50\% (Podsakoff, MacKenzie, Lee, and Podsakoff 2003). This supports technology embodiment as a multidimensional factor with the three first-order factors better explain the variance in the data.

$$
\begin{aligned}
& ==\text { Insert Table } 3 \text { about Here }== \\
& ==\text { Insert Table } 4 \text { about Here }==
\end{aligned}
$$

The fit indices also support the adequacy of the structural model to test the hypotheses (see Figure 1 for results of the structural model). First, the second order variable, Embodiment, shows significant paths to its subcomponents: Ownership $(\beta=.880, p=.000)$, Location $(\beta=$ $.720, p=.000)$, and Agency $(\beta=.664, p=.000)$. This result confirms that embodiment of 
wearable augmented reality is a multidimensional variable consisting of the feeling that technology is part of the body, that the vision perceived through the device is located at the same place where the tourists direct their gaze to, and that tourists has control over this vision (Hypothesis 1 was supported). Thus, this study corroborates the applicability of the embodiment scale developed by Longo et al. $(2008 ; 2009)$ and extends the context of study from RHI to wearable augmented reality. Importantly, this result also enriches the philosophical discussion on technology embodiment by providing empirical support for the phenomenological description of human - technology relation in situated experiences involving interactions with the world. That is, Ownership and Location explain how tourists perceive the state of technology withdrawal where the wearable device disappears (i.e., as if users looked directly at their surrounding environment instead of filtered through a screen in front of their eyes), becomes part of their action (i.e., the projected image was perceived as their own vision/eyesight), and extends their bodily capacity. This supports the hybridity of humans and technology in embodiment relation of technological mediation (Ihde 1990; 1993; Verbeek 2005; 2015). Further, Agency reflects the entanglement of subjectivity and objectivity in human - technology relation involving wearable devices, in that users feel that they are in control during the experience. In this case, tourists recognized that the image they perceive was a result of Google Glass pointing at paintings (i.e., the device presents them with augmented image; subjectivity lies with technology), but also felt that they were in control of the visuals presented to them, for example, by moving the device around (i.e., subjectivity lies with humans). Therefore, it can be suggested that Verbeek's (2007; 2008) proposition that subjectivism and objectivism are both the results of technological mediation is supported. 
Secondly, the results also show that technology Embodiment has a significant positive effect on Enjoyment $(\beta=.673, p=.000)$ and explains $45 \%$ variance in Enjoyment $\left(R^{2}=.453, p\right.$ $=.000)$. This confirms that when tourists embodied the wearable augmented reality device, they perceive the experience of seeing the exhibits to be enjoyable and interesting (Hypothesis 2 was supported). This supports the suggestion from previous studies on augmented reality that mixed reality sparks interest and heightens enjoyment (Bressler and Bodzin 2013; Morrison et al. 2009; Van der Heijden 2004), especially in hedonic experiences. Finally, the results also confirm that Embodiment has statistically significant positive influence on Experience $(\beta=.330, p=.001)$ and Enjoyment also significantly influences Experience $(\beta=.424, p=.000)$, explaining $48 \%$ variance in the overall Experience $\left(R^{2}=.477, p=.000\right)$. This confirms that technology embodiment has a direct effect on overall touristic experience as well as indirect effects through enjoyment (Hypotheses 3 and 4 were supported). The summary of hypothesis testing is presented in Table 5.

\section{$==$ Insert Table 5 about Here $==$}

In order to explore alternative explanations for the outcomes of technology embodiment, two null models (with higher degrees of freedom) were tested. Model 2 assesses the effects of technology embodiment on enjoyment and overall experience, but the effect of enjoyment on experience was eliminated (i.e., relaxing one parameter). The model was correctly identified and demonstrated a good fit $\left(\chi^{2}(147)=296.251, p=.000 ;\right.$ CFI $=.921 ;$ TLI $=.908 ;$ RMSEA $=.072$; SRMR $=.071)$. The Satorra-Bentler scaled $\chi^{2}$ difference test between the two models are presented in Table 6 . The $\chi^{2}$ difference was significant, indicating that adding one parameter (EN $\rightarrow \mathrm{EX})$ in Model 1 significantly improves the model $(T=12.735, p=.000)$. Model 3 assesses the effect embodiment on enjoyment and the effect of enjoyment on experience. The path from 
embodiment to experience was eliminated. The model was also correctly identified with a good fit $\left(\chi^{2}(147)=291.181, p=.000 ; \mathrm{CFI}=.924 ; \mathrm{TLI}=.912 ; \mathrm{RMSEA}=.071 ; \mathrm{SRMR}=.074\right)$. As seen in Table 6 , the $\chi^{2}$ difference was also significant, indicating that adding one parameter (EM $\rightarrow \mathrm{EX})$ in Model 1 significantly improves the model $(T=6.660, p=.010)$. Therefore, it can be concluded that Model 1 is significantly better than the two null models, providing further support for Hypotheses 3 and 4. The syntax for Models 1, 2, and 3 can be found in Appendix C.

$$
==\text { Insert Table } 6 \text { about Here }==
$$

In this study, the mediation of wearable augmented reality results in a transformed art gallery experience (i.e., the mesh between the paintings in the gallery with the additional information overlaid to it), which, in itself, is a manifestation of enhancement or improvement. The stronger tourists perceive the embodiment of Google Glass during their experiences with the paintings in the art gallery, the more they feel that Google Glass improves their experiences. Similarly, the stronger they embodied Google Glass, the more they perceive the experience to be fun and interesting, and, thus, feel that they have better experiences using Google Glass. This further confirms that tourists generally have positive attitude toward the transformed experiences, which is a result of technology - world relations (Brey 2000), as opposed to direct, non-mediated experiences.

\section{CONCLUSION}

Technology and digital media increasingly mediate tourist experiences (e.g., Jansson 2007;

Tussyadiah and Fesenmaier 2009) and the development of new technologies implies different ways of technological mediation. Technology devices are not only smaller and portable, the new breed of personal devices are developed to be wearable and, thus, integral to human actions. Due 
to the practical and theoretical importance of wearable technology in tourism, this research focuses on conceptualizing technological mediation involving the use of wearable computing devices by providing a critical reflection on theoretical perspectives underlying our understanding of human - technology relations in situated tourism experiences. Drawing on Ihde's $(1990 ; 1993)$ conceptualization of technological mediation, the basic tenet of neutrality of technology in mediated experiences is contested. That is, as technology stands in between humans and the world, it transformed human experiences, which engenders a form of subjectivity. That is, technology is non-neutral, but has a subjective role in mediated experiences. As Verbeek (2007) points out, the transformation in mediated experiences is a result of technology interacting with the world and offering the representation the world to its users (as in alterity relation). Therefore, it is argued that technological mediation results in both subjectivism and objectivism attached to humans and technology (Verbeek 2015). To explain this further, this study shows the phenomenon of embodiment relation in technological mediation (Ihde 1990; Verbeek $2007 ; 2008$ ) as it is manifested in actual experiences of tourists interacting with exhibits in an art gallery using augmented reality application on Google Glass. Specifically, the symbiosis of humans and technology as suggested in the philosophical discussion regarding embodiment relation is assessed in a psychometric approach using the introspective scale developed by Longo et al. (2008).

This research provides empirical support for the theories of technological mediation by defining and decomposing the structure of technology. Firstly, it elucidates the symbiosis of humans and technology in embodiment relation by describing the multidimensionality of embodiment as it is formed by three factors representing the feeling of ownership (i.e., technology as part of human bodies), location (i.e., co-presence of humans and technology), and 
agency (i.e., ability to control the relationship). This supports the standing that technology worn on the bodies tends to disappear while users perceive it as part of their bodies. In the context of this research, Google Glass integrates into the tourists' body schema and extends their perceptual skills (i.e., visual). Namely, head mounted Google Glass is not experienced as a spatial entity (i.e., tourists feel as if they look directly toward the paintings instead of through the screen), but becomes the medium where visual perception takes place as tourists point it toward the paintings. Therefore, this research supports the philosophical discussion on technology withdrawal in mediated experiences (Ihde 1990; Brey 2000).

Secondly, embodiment relation in touristic experiences decenters humans as the subject of human - technology interactions and verifies the non-neutrality of technology in mediated experiences. Tourists recognize that the image they perceive through Google Glass screen is a result of the device pointing at the paintings, which entails processes of interaction between the device and the paintings through sensors. This signifies that by interacting with the world, technology manipulates (i.e., augments, enhances) the representation of the world and, therefore, transforms users' perception. This supports the notion that mediators at times become surrogate parents (Urry and Larsen 2011), where the world experienced by the tourists are constructed and, thus, transformed, by the mediators (in this case, technology mediators). The agency factor (i.e., the notion of control) brings subjectivity to the fore of embodiment relation, in that while technology possesses artifactual intentionality to transform human experiences (Ihde 1990; Verbeek 2005; 2007; 2008), this intentionality is coupled with that of its users to interact with the world. Therefore, technology (e.g., Google Glass) is not the terminus of experience (i.e., as in alterity relation), the world (e.g., the painting) is. 
Thirdly, extending and confirming the applicability of Longo et al.'s (2008) scale to wearable augmented reality confirms embodiment as a coherent psychological construct. This is particularly relevant in the context of tourism management where the quality of technologymediated experiences is of important concerns. Testing the multidimensionality of embodiment in actual experiences provides consistency with previous conceptual and experimental studies on technology embodiment. At the same time, it bridges the theory and practice by specifying key aspects supporting technology embodiment. Tourism providers interested in investing on wearable augmented reality technology should place an importance on the subcomponents of technology embodiment to better mediate tourist experiences with wearable technology. For example, wearable technology should be designed in ways that it extends, but not constraints the human bodies, so it will integrate seamlessly with its users' actions. It implies the importance of designing the shapes, sizes, appearances, and placements of technology devices relative to human bodies so they will be perceived as part or extension of the "subject bodies." As illustrated by Ihde $(1990 ; 1993)$, eyeglasses are embodied by the users as they "disappear" in everyday actions. Similar to eyeglasses, Google Glass provides a more natural mode of interaction in a tour or sightseeing compared to hand-held devices where users need to hold an additional screen to bridge them with the natural environment around them. Visitors to a tourism attraction will forget that they are even wearing Google Glass as the Cards will appear subtly when needed (McGee, 2014). It can be suggested that smart glasses should be used for applications that primarily deliver visual sensations (e.g., virtual, augmented, or mixed reality) to support the perception of ownership and location. In order to facilitate the perception of agency, it is important for the applications to allow different mode of interactions (e.g., haptic or voice commands, body movements) to ensure that users feel in control of their augmented reality 
experience. Furthermore, the results indicate that embodiment has positive impacts on enjoyment and overall experiences interacting with exhibits in the art gallery. For tourism providers, it signifies the positive roles of technology in enhancing experiences in tourism attractions and justifies the investment in innovative technologies for tourism experiences.

Lastly, through a review of conceptual description of embodiment phenomenon and an application of the psychometric approach to embodiment, this research contributes to a better positioning of technological mediation in tourism involving the latest wearable technology. However, several limitations remain. This research clarifies the dynamics of humans technology relation within the mediated experiences, which is the underlined part of the schema (Verbeek 2005; 2007; 2008): [Tourists - Technology] $\rightarrow$ Tourism Destinations. Naturally, the challenge on subjectivism and objectivism as well as the interplay of intentionality is centered in this relation, which is the core of embodiment. However, a deeper look on the subjectivity and objectivity between the two entities and the world (e.g., how tourists embody tourism destinations with the help of wearable technology) remains unexplained and should be considered in future research. Also, the experiential nature of this research constraints the research design and data gathering methods. Focusing on an art gallery allows the measuring of consistent experiences as all participants go through and interact with the same exhibits without much distraction from a multitude of other natural objects and situational contexts (e.g., in cases of walking around a city). Consequently, the results may not represent general embodiment experiences in other tourism settings. Therefore, future studies should apply the assessment of embodiment in different types of tourism attractions and settings. Additionally, the intensive nature of data collection limited the number of participants to be included in the study. While the 
results obtained from the analysis demonstrate a good fit, future studies should incorporate a larger number of respondents to test the model further.

\section{References}

Anderson, J.C., and D.W. Gerbing. 1988. "Structural Equation Modeling in Practice: A Review and Recommended Two-Step Approach.” Psychological Bulletin 103(3): 411-423.

Azuma, R.T. 1997. “A Survey of Augmented Reality.” Presence: Teleoperators and Virtual Environments 6(4): 355-385.

Barfield, W., and T. Caudell. 2001. "Basic Concepts in Wearable Computers and Augmented Reality." In Fundamentals of Wearable Computers and Augmented Reality, edited by W. Barfield and T. Caudell. Boca Raton, FL: CRC Press.

Barfield, W., Bressler, D.M., and A.M. Bodzin. 2013. “A Mixed Methods Assessment of Students' Flow Experiences during a Mobile Augmented Reality Science Game.” Journal of Computer Assisted Learning 29: 505-517.

Bentler, P.M., and C.H. Chou. 1987. "Practical Issues in Structural Modeling." Sociological Methods \& Research 16: 78-117.

Brey, P. 2000. “Technology and Embodiment in Ihde and Merleau-Ponty.” In Metaphysics, Epistemology, and Technology. Research in Philosophy and Technology (Vol. 19), edited by C. Mitcham. London: Elsevier/JAI Press.

Caggianese, G., P. Neroni, and L. Gallo. 2014. "Natural Interaction and Wearable Augmented Reality for the Enjoyment of the Cultural Heritage in Outdoor Conditions." In AVR 2014, LNCS 8853, edited by L.T. De Paolis and A. Mongelli, 267-282. Switzerland: Springer. 
Chin, W.W. 1998. "Issues and Opinions on Structural Equation Modeling.” MIS Quarterly, 22, vii-xvi.

Chung, N., H. Han, and Y. Joun. 2015. "Tourists' Intention to Visit a Destination: The Role of Augmented Reality (AR) Application for a Heritage Site.” Computers in Human Behaviour 50: 588-599.

Cohen, E. (1979). “A phenomenology of Tourist Experience.” Sociology 13(2): 179-201.

ComScore, Inc. 2011. "Digital Omnivores: How Tablets, Smartphones and Connected Devices are Changing U.S. Digital Media Consumption Habits." Retrieved from http://www.iab.net/media/file/Digital\%2BOmnivores.pdf

Consumer Electronics Association (CEA). 2015. "New Category Excitement Drives Increase in Consumer Tech Spending.” Retrieved from http://www.ce.org/News/NewsReleases/Press-Releases/2015-Press-Releases/New-Category-Excitement-DrivesIncrease-in-Consume.aspx

Damala, A., I. Marchal, and P. Houlier. 2007. "Merging Augmented Reality Based Features in Mobile Multimedia Museum Guides: Anticipating the Future of the Cultural Past.” In Proceedings of CIPA Conference (pp. 259-264), Athens, Greece, 1-6 October 2007.

Davis, F.D., R.P. Bagozzi, and P.R. Warshaw. 1992. "Extrinsic and Intrinsic Motivation to Use Computers in the Workplace.” Journal of Applied Social Psychology 11: 1111-1132.

Dickey, M.R. 2013. “How Google Glass will Revolutionize 9 Industries.” Retrieved from http://www.businessinsider.com/google-glass-will-totally-disrupt-these-tktk-industries2013-3?op=1 
Ding, L., W.F. Velicer, and L.L. Harlow (1995). "Effects of Estimation Methods, Number of Indicators per Factor, and Improper Solutions on Structural Equation Modeling Fit Indices.” Structural Equation Modeling 2(2): 119-144.

Edensor, T. 2001. "Performing Tourism, Staging Tourism: (Re)Producing Tourist Space and Practice.” Tourist Studies 1(1): 59-81.

Feiner, S., B. MacIntyre, T. Höllerer, and A. Webster. 1997. “A Tourism Machine: Prototyping 3D Mobile Augmented Reality Systems for Exploring the Urban Environment.” In Proceedings of First International Symposium on Wearable Computers (p. 74-81), Cambridge, MA, October 13 - 14, 1997.

Fritz, F., A. Susperregui, and M.T. Linaza. 2005. "Enhancing Cultural Tourism Experiences with Augmented Reality Technologies.' In Proceedings of the $6^{\text {th }}$ International Symposium on Virtual Reality, Archaeology and Cultural Heritage, Pisa, Italy, November 9, 2005.

Fuchs, T., and J.E. Schlimme. 2009. "Embodiment and Psychopathology: A Phenomenological Perspective.” Current Opinion in Psychiatry 22: 570-575.

Gallagher, S. 1986. "Body Image and Body Schema: A Conceptual Clarification.” Journal of Mind and Behavior 7: 541-554.

Gefen, D., D.W. Straub, and M. Boudreau. 2000. "Structural Equation Modeling and Regression: Guidelines for Research Practice." Communications of the Association of Information Systems, 4, 1-78.

Gellersen, H.-W. 1999. “Guest Editorial: Handheld CSCW: Personal Technologies for Collaboration." Personal Technologies 3(1-2): 1-7. 
Giraud, T., A. Paljic, and L. Leroy. 2013. ““'It” + “I”: Virtual Embodiments as Hybrid

Experiences." In Proceedings of the $5^{\text {th }}$ Joint Virtual Reality Conference (pp. 91-94), Aire-la-Ville, Switzerland, December 11, 2013.

Gleue, T., and P. Dähne. 2001. "Design and Implementation of a Mobile Device for Outdoor Augmented Reality in the Archeoguide Project." In Proceedings of the 2001 Conference on Virtual Reality, Archeology, and Cultural Heritage. New York: ACM.

Google, Inc. 2012. “Glass Explorer Program.” Google.com/Glass

Hair, J.F. Jr., W.C. Black, B.J. Babin, and R.E. Anderson. 2010. Multivariate Data Analysis. 7th Edition. Upper Saddle River, NJ: Prentice Hall.

Hair, J.F., C.M. Ringle, and M. Sarstedt. 2011. “PLS-SEM: Indeed a Silver Bullet.” Journal of Marketing Theory and Practice, 19, 139-152.

Han, D., T. Jung, and A. Gibson. 2014. "Dublin AR: Implementing Augmented Reality (AR) in Tourism.” In Information and Communication Technologies in Tourism 2014, edited by Z. Xiang and I. Tussyadiah, I., 511-523. Switzerland: Springer International Publishing. Holloway, J.C. 1981. “The Guided Tour: A Sociological Approach.” Annals of Tourism Research 8(3): 377-402.

Hu, L., and P.M. Bentler. 1999. "Cutoff Criteria for Fit Indexes in Covariance Structure Analysis: Conventional Criteria versus New Alternatives." Structural Equation Modeling: A Multidisciplinary Journal 6(1): 1-55.

Igbaria, M., S. Parasuraman, and J. Baroudi. 1996. "A Motivational Model of Microcomputer Usage.” Journal of Management Information Systems 13(1): 127-143.

Ihde, D. 1990. Technology and the Lifeworld: From Garden to Earth. Bloomington, IN: Indiana University Press. 
Ihde, D. 1993. The Philosophy of Technology. New York, NY: Paragon House.

Iso-Ahola, S. 1984. "Social psychological foundations of leisure and resultant implications for leisure counseling.” In Leisure Counseling: Concepts and Applications, edited by E. T. Dowd, 97-125. Springfield, Illinois: Charles C. Thomas.

Jansson, A. 2012. "Spatial Phantasmagoria: The Mediatization of Tourism Experience." European Journal of Communication 17(4): 429-443.

Jennings, G., and B. Weiler. 2006. "Mediating Meaning: Perspectives on Brokering Quality Tourist Experiences.” In Quality Tourism Experiences, edited by G. Jennings and N. P. Nickerson, 57-78. Boston: Elsevier.

Jensen, O. 2010. "Social Mediation in Remote Developing World Tourism Locations - The Significance of Social Ties Between Local Guides and Host Communities in Sustainable Tourism Development.” Journal of Sustainable Tourism 18(5): 615-633.

Johsnston, L. 2001. “(Other) Bodies and Tourism Studies.” Annals of Tourism Research 28(1): 180-201.

Jung, T., N. Chung, and M. Leue. 2015. The Determinants of Recommendations to Use Augmented Reality Technologies - The Case of a Korean Theme Park." Tourism Management 49: 75-86.

Kounavis, C.D., A.E. Kasimati, and E.D. Zamani. 2012. "Enhancing the Tourism Experience through Mobile Augmented Reality: Challenges and Prospects.” International Journal of Engineering Business Management 4: 1-6.

Leue, M.C., D. Han, and T. Jung. 2014. “Google Glass Creative Tourism Experience: A Case Study of Manchester Art Gallery.” Paper presented at WHTF, Seoul, 26-29 June 2014. 
Leue, M.C., T. Jung, and D. tom Dieck. 2015. Google Glass Augmented Reality: Generic Learning Outcomes for Art Galleries. In Information and Communication Technologies in Tourism 2015, edited by I. Tussyadiah and A. Inversini, 463-476. Switzerland: Springer International Publishing.

Longo, M. R., \& P. Haggard. 2012. "What is it Like to Have a Body?" Current Directions in Psychological Science 21: 140-145.

Longo, M.R., Schüür, F., Kammers, M.P.M., Tsakiris, M., \& Haggard, P. 2008. "What is Embodiment? A Psychometric Approach.” Cognition 107: 978-998.

Longo, M.R., F. Schüür, M.P.M. Kammers, M. Tsakiris, and P. Haggard. 2009. "Self Awareness and the Body Image.” Acta Psychologica 132(2): 166-172.

Lowry, P.J., and J. Gaskin. 2014. "Partial Least Squares (PLS) Structural Equation Modeling (SEM) for Building and Testing Behavioral Causal Theory: When to Choose it and How to Choose it." IEEE Transactions on Professional Communication 57(2): 123-146.

MacCallum, R.C., M.W. Browne, and H.M. Sugawara. 1996. "Power Analysis and Determination of Sample Size for Covariance Structural Modeling." Psychological Methods 17: 23-41.

MacCannell, D. 1989. The Tourist: A New Theory of the Leisured Class. New York: Schocken Books.

Macdonald, S. 2006. "Mediating Heritage: Tour Guides at the Former Nazi Party Rally Grounds, Nuremberg." Tourist Studies 6(2): 119-138.

Macvean, A.P., and M.O. Riedl. 2011. "An Enjoyment Metric for the Evaluation of Alternate Reality Games." In Proceedings of the $6^{\text {th }}$ International Conference on Foundations of Digital Games, 277-279. New York, NY: ACM. DOI: 10.1145/2159365.2159411. 
Mannell, R., and S.E. Iso-Ahola. 1987. "Psychological Nature of Leisure and Tourism Experience.” Annals of Tourism Research 14: 314-331.

McGee, M. 2014, December 4. "San Francisco Museum is First to offer Google Glass-Powered Art Exhibit." Glass Almanac. Retrieved from http://glassalmanac.com/san-franciscomuseum-first-offer-google-glass-powered-art-exhibit/6717/.

McGrath, G. 2007. Towards Developing Tour Guides as Interpreters of Cultural Heritage: The Case of Cusco, Peru. In Quality Assurance and Certification in Ecotourism, edited by R. Black and A. Crabtree, 364-394. Oxfordshire: CAB International.

Merleau-Ponty, M. 1962. Phenomenology of Perception. Translated by C. Smith. London: Routledge.

Morrison, A., A. Oulasvirta, P. Peltonen, S. Lemmelä, G. Jacucci, G. Reitmayr, J. Näsänen, and A. Juustila. 2009. "Like Bees around the Hive: A Comparison Study of a Mobile Augmented Reality Map.” In Proceedings of CHI 2009 Conference, Boston, MA, April 29, 2009.

Muthén, L.K., and B.O. Muthén. 1998-2012. Mplus User's Guide. Seventh Edition. Los Angeles, CA: Muthén \& Muthén.

Muthén L.K., and B.O. Muthén. 2002. "How to use a Monte Carlo study to decide on sample size and determine power." Structural Equation Modeling 4: 599-620.

Neuhofer, B., D. Buhalis, and A. Ladkin. 2012. “Conceptualising Technology Enhanced Destination Experiences.” Journal of Destination Marketing \& Management 1: 36-46. Nielsen (2014). “How Smartphones are Changing Consumers' Daily Routines around the Globe." Retrieved from 
http://www.nielsen.com/content/corporate/us/en/insights/news/2014/how-smartphonesare-changing-consumers-daily-routines-around-the-globe.html

Nunnally, J.C. 1967. "Psychometric Theory.” New York, NY: McGraw-Hill.

Oulasvirta, A., T. Rattenbury, L. Ma, and E. Raita. 2012. "Habits Make Smartphone Use More Pervasive." Personal and Ubiquitous Computing 16(1): 105-114.

Penn, M. 2015. "Views from around the Globe: $2^{\text {nd }}$ Annual Poll on How Personal Technology is Changing our Lives.” Microsoft. Retrieved from http://mscorp.blob.core.windows.net/mscorpmedia/2015/01/2015DavosPollFINAL.pdf

Podsakoff, P.M., S.B. MacKenzie, J.Y. Lee, and N.P. Podsakoff. 2003. "Common Method Biases in Behavioral Research: A Critical Review of The Literature and Recommended Remedies.” Journal of Applied Psychology 88(5): 879-903.

Prabu, K. 2012. “How Google's Project Glass is going to Revolutionize Travellers and Travel Companies.” Retrieved from http://www.travopia.com/2012/04/how-googles-projectglass-is-going-to.html

Price, T.F., C.K. Peterson, and E. Harmon-Jones. 2012. "The Emotive Neuroscience of Embodiment." Motivation and Emotion 36(1): 27-37.

Rauschnabel, P. A., A. Brem and B.S. Ivens, B. 2015. "Who will buy smart glasses? Empirical results of two pre-market-entry studies on the role of personality in individual awareness and intended adoption of Google Glass wearables." Computers in Human Behavior 49: 635-647.

Rossel, P. 1988. “Tourism and Cultural Minorities: Double Marginalization and Survival Strategies." In Tourism: Manufacturing the Exotic, edited by P. Rossel, 1-20. Copenhagen, Denmark: International Work Group for Indigenous Affairs. 
Stanghellini, G. 2009. “Embodiment and Schizophrenia.” World Psychiatry 8: 56-59.

Starner, T. 2015. "Wearable Computing: Meeting the Challenge." In Fundamentals of Wearable Computers and Augmented Reality ( ${ }^{\text {nd }}$ Edition), edited by W. Barfield, 13-30. Boca Raton, FL: CRC Press.

Starner, T., S. Mann, B. Rhodes, J. Levine, J. Healey, D. Kirsch, R. Picard, and A. Pentland. 1997. "Augmented Reality through Wearable Computing." Presence: Teleoperators and Virtual Environments 6(4): 386-398.

Statista 2016. "Share of Adults Who Visited a Museum or Gallery in the Last Year in England from 2012/13 to 2014/15, by Age." Retrieved from https://www.statista.com/statistics/418323/museum-galery-attendance-uk-england-byage/

Sylaiou, S., K. Mania, A. Karoulis, and M. White. 2010. "Exploring the Relationship between Presence and Enjoyment in a Virtual Museum." International Journal of HumanComputer Studies 68: 243-253.

Thong, J.Y.L., S.-J. Hong, and K.Y. Tam. 2006. "The Effects of Post-Adoption Beliefs on the Expectation-Confirmation for Information Technology Continuance." International Journal of Human-Computer Studies 64(9): 799-810.

Tinsley, H.E., and D.J. Tinsley. 1987. "Uses of Factor Analysis in Counseling Psychology Research.” Journal of Counseling Psychology 34(4): 414-424.

tom Dieck, M.C., and T. Jung. 2015. “A Theoretical Model of Augmented Reality Acceptance in Urban Heritage Tourism." Current Issues in Tourism. DOI: $10.1080 / 13683500.2015 .1070801$ 
tom Dieck, M. C., T. Jung, T. and D. Han. 2016. "Mapping requirements for the wearable smart glasses augmented reality museum application”. Journal of Hospitality and Tourism Technology 7(3): 230-253.

tom Dieck, M. C., T. Jung, T. and D. tom Dieck. 2016. “Enhancing art gallery visitors' learning experience using wearable augmented reality: generic learning outcomes perspective." Current Issues in Tourism: 1-21. DOI: 10.1080/13683500.2016.1224818

Turner, V. 1973. “The Center Out There: Pilgrims' Goal.” History of Religion 12: 191-230. Turner, L. and J. Ash. 1975. “The” Golden Hordes: International Tourism and the Pleasure Periphery. London: Constable \& Robinson Ltd.

Tussyadiah, I.P. 2012. “A Concept of Location-Based Social Network Marketing.” Journal of Travel and Tourism Marketing 29(3): 205-220.

Tussyadiah, I. 2014. "Expectation of Travel Experiences with Wearable Computing Devices.” In Information and Communication Technologies in Tourism 2014, edited by Z. Xiang and I. Tussyadiah, 539-552. Switzerland: Springer International Publishing.

Tussyadiah, I.P. 2015. "The Influence of Innovativeness on On-Site Smartphone Use among American Travelers: Implications for Context-based Push Marketing.” Journal of Travel and Tourism Marketing. DOI: 10.1080/10548408.2015.1068263.

Tussyadiah, I.P., and D.R. Fesenmaier. 2009. "Mediating Tourist Experiences - Access to Places via Shared Videos.” Annals of Tourism Research 36(1): 24-40

Tussyadiah, I.P., and F. Zach. 2012. "The Role of Geo-Based Technology in Place Experiences.” Annals of Tourism Research 39(2): 780-800.

Urry, J. 2002. The Tourist Gaze. $2^{\text {nd }}$ Edition. London: Sage Publications.

Urry, J., and J. Larsen. 2011. The Tourist Gaze 3.0. London: Sage Publications. 
Van der Heijden, H. 2004. "User Acceptance of Hedonic Information Systems.” MIS Quarterly 28(4): 695-704.

van Krevelen, D.W.F., and R. Poelman. 2010. "A Survey of Augmented Reality Technologies, Applications, and Limitations.” The International Journal of Virtual Reality 9(2): 1-20.

Veijola, S., and E. Jokinen. 1994. "The Body in Tourism.” Theory, Culture, \& Society 11(3): 125-151.

Venkatesh, V. 1999. "Creation of Favorable User Perceptions: Exploring the Role of Intrinsic Motivation.” MIS Quarterly 23(2): 239-260.

Venkatesh, V., and S.A. Brown. 2001. "A Longitudinal Investigation of Personal Computers in Homes: Adoption Determinants and Emerging Challenges.” MIS Quarterly 25(1): 71102.

Verbeek, P.-P. 2005. What Things Do: Philosophical Reflections on Technology, Agency, and Design. Translated by R. P. Crease. University Park, PA: The Pennsylvania State University Press.

Verbeek, P.-P. 2007. "Beyond the Human Eye: Technological Mediation and Posthuman Visions.” In Mediated Vision, edited by P. Kockelkoren. Rotterdam: Veenman Publishers and ArtEZ Press.

Verbeek, P.-P. 2008. “Cyborg Intentionality: Rethinking the Phenomenology of HumanTechnology Relations.” Phenomenology and the Cognitive Sciences 7(3): 387-395.

Verbeek, P.-P. 2015. "Beyond Interaction: A Short Introduction to Mediation Theory." Interactions 12(3): 26-31.

Wang, D., S. Park, and D.R. Fesenmaier. 2012. "The Role of Smartphones in Mediating the Touristic Experience.” Journal of Travel Research 51(4): 371-387. 
Wang, D., Z. Xiang, and D.R. Fesenmaier. 2014a. "Adapting to the Mobile World: A Model of Smartphone Use.” Annals of Tourism Research 48: 11-26

Wang, D., Z. Xiang, and D.R. Fesenmaier. 2014b, OnlineFirst. "Smartphone Use in Everyday Life and Travel.” Journal of Travel Research. DOI: 10.1177/0047287514535847

Weiler, B., and X. Yu. 2007. "Dimensions of Cultural Mediation in Guiding Chinese Tour Groups: Implications for Interpretation.” Tourism Recreation Research 32(3): 13-22.

Weiss, T., C. Whiteley, J. Treviranus, and D.I. Fels. 2001. "PEBBLES: A Personal Technology for Meeting Educational, Social and Emotional Needs of Hospitalized Children." Personal and Ubiquitous Computing 5: 157-168.

Wise, J. M. 1997. Exploring Technology and Social Space. Thousand Oaks, NJ: Sage Publications.

Wise, J. M. 1998. "Intelligent Agency." Cultural Studies 12(3): 410-428.

Wojciechowski, R., K. Walczak, M. White, and W. Cellary. 2004. "Building Virtual and Augmented Reality Museum Exhibitions.” In Proceedings of the Web3D 2004 Symposium - the $9^{\text {th }}$ International Conference on 3D Web Technology (ACM SIGGRAPH), Monterey, CA, pp. 135-144.

Yovcheva, Z., D. Buhalis, and C. Gatzidis. 2011. “Overview of Smartphone Augmented Reality Applications for Tourism.” e-Review of Tourism Research (eRTR) 10(2): 63-66.

Yovcheva, Z., D. Buhalis, C. Gatzidis, and C. van Elzakker. 2014. "Empirical Evaluation of Smartphone Augmented Reality Browsers in an Urban Tourism Destination Context." International Journal of Mobile Human Computer Interaction 6(2): 10-31. 


\section{Appendix}

\section{A. Measurement Items}

Ownership (OW): 1 (Strongly Disagree) - 7 (Strongly Agree)

When looking at the painting through Google Glass AR application...

OW1 - ...it seemed like I was looking directly at my own surrounding environment, rather than at a Google Glass screen.

OW2 - ...it seemed like the image I saw through the Google Glass screen resembled my own surrounding environment.

OW3 - ...it seemed like the image I saw through the Google Glass screen was my own vision.

OW4 - ...it seemed like the image I saw through the Google Glass screen was part of my surrounding environment.

OW5 - ...it seemed like the image I saw on the Google Glass screen was my own eyesight.

Location (LO): 1 (Strongly Disagree) - 7 (Strongly Agree)

When looking at the painting through Google Glass AR application...

LO1 - ...it seemed like the image I saw through the Google Glass screen was in the location where I was.

$\mathrm{LO} 2$ - ...it seemed like I was in the location where the vision on the Google Glass screen was.

LO3 - ...it seemed like the image I saw through the screen was caused by the Google Glass pointing at the painting.

LO4 - ...it seemed like I was recognizing an image in the location where the painting was.

Agency (AG): 1 (Strongly Disagree) - 7 (Strongly Agree)

When looking at the painting through Google Glass AR application...

AG1 - ...it seemed like I could have moved the Google Glass vision around if I had wanted. 
AG2 - ...it seemed like I was in control of the Google Glass vision.

AG3 - ...it seemed like my own surrounding environment became the Google Glass vision.

AG4 - ...it seemed like I was in control of the visuals on the Google Glass screen.

Enjoyment (EN): 1 (Strongly Disagree) - 7 (Strongly Agree)

EN1 - Looking at the paintings through Google Glass was enjoyable.

EN2 - Looking at the paintings through Google Glass was interesting.

EN3 - Looking at the paintings through Google Glass was pleasant.

Experience (EX): 1 (Strongly Disagree) - 7 (Strongly Agree)

EX1 - Google Glass improves my experience with the paintings.

EX2 - Google Glass enhances my experience with the paintings.

EX3 - Using Google Glass, I had a better experience with the paintings.

\section{B. Examples of Museum Zoom Google Glass Cards}

Cheetah and Stag with

Two Indians

by George Stubbs 


\section{Date: ca. 1765}

Creation place: Windsor Park Medium: Oil on canvas

Display Dimensions: 33 5/8 in. $\times 527 / 8$ in $(85.41 \mathrm{~cm} \times 134.3 \mathrm{~cm})$

Ocasion: Gift of a Cheetah to the Duke of Cumberland

\section{Syntax for Models 1, 2 and 3 with MLM Parameter Estimates}

\begin{tabular}{|c|c|c|}
\hline Model 1 & Model 2 & Model 3 \\
\hline $\begin{array}{l}\text { DATA: FILE IS “*`GLASS.csv”; } \\
\text { LISTWISE=ON; }\end{array}$ & $\begin{array}{l}\text { DATA: FILE IS “*`GGASS.csv”; } \\
\text { LISTWISE=ON; }\end{array}$ & $\begin{array}{l}\text { DATA: FILE IS “*|GLASS.csv”; } \\
\text { LISTWISE=ON; }\end{array}$ \\
\hline $\begin{array}{l}\text { VARIABLE: NAMES ARE OW1- } \\
\text { OW5 LO1-LO4 AG1-AG4 EN1- } \\
\text { EN3 EX1-EX3; } \\
\text { USEVARIABLES ARE OW1- } \\
\text { OW5 LO1-LO4 AG1-AG4 EN1- } \\
\text { EN3 EX1-EX3; }\end{array}$ & $\begin{array}{l}\text { VARIABLE: NAMES ARE OW1- } \\
\text { OW5 LO1-LO4 AG1-AG4 EN1- } \\
\text { EN3 EX1-EX3; } \\
\text { USEVARIABLES ARE OW1- } \\
\text { OW5 LO1-LO4 AG1-AG4 EN1- } \\
\text { EN3 EX1-EX3; }\end{array}$ & $\begin{array}{l}\text { VARIABLE: NAMES ARE OW1- } \\
\text { OW5 LO1-LO4 AG1-AG4 EN1- } \\
\text { EN3 EX1-EX3; } \\
\text { USEVARIABLES ARE OW1- } \\
\text { OW5 LO1-LO4 AG1-AG4 EN1- } \\
\text { EN3 EX1-EX3; }\end{array}$ \\
\hline $\begin{array}{l}\text { ANALYSIS: } \\
\text { ESTIMATOR=MLM; }\end{array}$ & $\begin{array}{l}\text { ANALYSIS: } \\
\text { ESTIMATOR=MLM; }\end{array}$ & $\begin{array}{l}\text { ANALYSIS: } \\
\text { ESTIMATOR=MLM; }\end{array}$ \\
\hline $\begin{array}{l}\text { MODEL: } \\
\text { OW BY OW1-OW5; } \\
\text { LO BY LO1-LO4; } \\
\text { AG BY AG1-AG4; } \\
\text { EN BY EN1-EN3; } \\
\text { EX BY EX1-EX3; } \\
\text { EM BY OW LO AG; } \\
\text { EN ON EM; } \\
\text { EX ON EM EN; }\end{array}$ & $\begin{array}{l}\text { MODEL: } \\
\text { OW BY OW1-OW5; } \\
\text { LO BY LO1-LO4; } \\
\text { AG BY AG1-AG4; } \\
\text { EN BY EN1-EN3; } \\
\text { EX BY EX1-EX3; } \\
\text { EM BY OW LO AG; } \\
\text { EN ON EM; } \\
\text { EX ON EM EN@0; }\end{array}$ & $\begin{array}{l}\text { MODEL: } \\
\text { OW BY OW1-OW5; } \\
\text { LO BY LO1-LO4; } \\
\text { AG BY AG1-AG4; } \\
\text { EN BY EN1-EN3; } \\
\text { EX BY EX1-EX3; } \\
\text { EM BY OW LO AG; } \\
\text { EN ON EM; } \\
\text { EX ON EM@0 EN; }\end{array}$ \\
\hline
\end{tabular}


Table 1. Characteristics of Respondents

\begin{tabular}{|c|c|c|c|c|c|}
\hline & \multicolumn{2}{|c|}{ Phase 1} & \multicolumn{2}{|c|}{ Phase 2} & \multirow[t]{2}{*}{$\chi^{2}(p)$} \\
\hline & & $\%$ & $\mathbf{N}$ & $\%$ & \\
\hline Gender & & & & & $.030(.842)$ \\
\hline Male & 66 & $53 \%$ & 36 & $55 \%$ & \\
\hline Female & 58 & $47 \%$ & 30 & $45 \%$ & \\
\hline Age & & & & & $1.228(.942)$ \\
\hline $18-24$ & 37 & $30 \%$ & 18 & $27 \%$ & \\
\hline $25-44$ & 50 & $40 \%$ & 31 & $47 \%$ & \\
\hline $45-64$ & 25 & $20 \%$ & 12 & $19 \%$ & \\
\hline $65+$ & 12 & $10 \%$ & 5 & $8 \%$ & \\
\hline Education & & & & & $1.037(.984)$ \\
\hline High School & 10 & $8 \%$ & 7 & $11 \%$ & \\
\hline Some College & 15 & $12 \%$ & 7 & $11 \%$ & \\
\hline Associate Degree/Diploma & 14 & $11 \%$ & 7 & $11 \%$ & \\
\hline Bachelor's Degree & 45 & $36 \%$ & 27 & $41 \%$ & \\
\hline Master's Degree & 28 & $22 \%$ & 13 & $20 \%$ & \\
\hline Doctoral Degree & 6 & $5 \%$ & 2 & $3 \%$ & \\
\hline Advanced Professional Degree & 7 & $6 \%$ & 3 & $5 \%$ & \\
\hline Income & & & & & $6.378(.956)$ \\
\hline$£ 13000$ or less & 38 & $32 \%$ & 17 & $27 \%$ & \\
\hline$£ 13001-£ 20000$ & 12 & $10 \%$ & 10 & $16 \%$ & \\
\hline$£ 20001-£ 26000$ & 18 & $15 \%$ & 11 & $18 \%$ & \\
\hline$£ 26001-£ 32000$ & 5 & $4 \%$ & 2 & $3 \%$ & \\
\hline$£ 32001-£ 39000$ & 8 & $7 \%$ & 2 & $3 \%$ & \\
\hline$£ 39001-£ 45000$ & 9 & $8 \%$ & 5 & $8 \%$ & \\
\hline$£ 45001-£ 52000$ & 5 & $4 \%$ & 4 & $6 \%$ & \\
\hline$£ 52001-£ 58000$ & 4 & $3 \%$ & 2 & $3 \%$ & \\
\hline$£ 58001-£ 64000$ & 4 & $3 \%$ & 4 & $6 \%$ & \\
\hline$£ 64001-£ 70500$ & 3 & $3 \%$ & 1 & $2 \%$ & \\
\hline$£ 70501-£ 77000$ & 3 & $3 \%$ & 1 & $2 \%$ & \\
\hline$£ 77001-£ 83000$ & 2 & $2 \%$ & 0 & $0 \%$ & \\
\hline$£ 83001-£ 90000$ & 1 & $1 \%$ & 1 & $2 \%$ & \\
\hline$£ 90001$ or more & 7 & $6 \%$ & 2 & $3 \%$ & \\
\hline
\end{tabular}

Note: Demographic questions were made optional to answer. 
Table 2. Descriptive Statistics of Variables and Results of Normality Test

\begin{tabular}{|c|c|c|c|c|c|c|}
\hline \multirow{2}{*}{ Items } & \multirow{2}{*}{ Mean } & \multirow{2}{*}{ St. Dev. } & \multirow{2}{*}{$\begin{array}{c}\text { Skewness } \\
(\text { S.E. }=.174)\end{array}$} & \multirow{2}{*}{$\begin{array}{c}\text { Kurtosis } \\
(\text { S.E. }=.346)\end{array}$} & \multicolumn{2}{|c|}{ Kolmogorov-Smirnov Test } \\
\hline & & & & & $D(195)$ & $p$ \\
\hline OW1 & 4.68 & 1.458 & -.562 & -.659 & .224 & .000 \\
\hline OW2 & 4.59 & 1.456 & -.616 & -.481 & .230 & .000 \\
\hline OW3 & 4.56 & 1.592 & -.513 & -.755 & .228 & .000 \\
\hline OW4 & 4.76 & 1.456 & -.575 & -.449 & .216 & .000 \\
\hline OW5 & 4.45 & 1.628 & -.421 & -.748 & .213 & .000 \\
\hline LO1 & 5.22 & 1.375 & -1.007 & .375 & .259 & .000 \\
\hline $\mathrm{LO} 2$ & 4.95 & 1.433 & -.767 & -.113 & .205 & .000 \\
\hline LO3 & 5.04 & 1.335 & -.864 & .368 & .216 & .000 \\
\hline LO4 & 5.24 & 1.247 & -.967 & .520 & .231 & .000 \\
\hline AG1 & 5.05 & 1.488 & -.924 & .015 & .251 & .000 \\
\hline AG2 & 5.38 & 1.236 & -.949 & .674 & .255 & .000 \\
\hline AG3 & 4.47 & 1.561 & -.398 & -.855 & .188 & .000 \\
\hline AG4 & 5.51 & 1.095 & -.865 & .600 & .262 & .000 \\
\hline EN1 & 5.62 & 1.244 & -1.103 & .887 & .273 & .000 \\
\hline EN2 & 6.18 & .728 & -.533 & -.141 & .244 & .000 \\
\hline EN3 & 5.52 & 1.298 & -.988 & .554 & .249 & .000 \\
\hline EX1 & 5.46 & 1.329 & -.962 & .484 & .237 & .000 \\
\hline EX2 & 5.68 & 1.237 & -1.115 & 1.350 & .239 & .000 \\
\hline EX3 & 5.44 & 1.400 & -.710 & -.252 & .214 & .000 \\
\hline
\end{tabular}

Table 3. Factor Loadings, Average Variance Extracted (AVE) and Composite Reliability (CR)

\begin{tabular}{|c|c|c|c|}
\hline Factors / Items & Factor Loadings & AVE & CR \\
\hline Ownership (OW) & & .605 & .884 \\
\hline $\mathrm{OW} \rightarrow \mathrm{OW} 1$ & .656 & & \\
\hline $\mathrm{OW} \rightarrow \mathrm{OW} 2$ & .733 & & \\
\hline $\mathrm{OW} \rightarrow \mathrm{OW} 3$ & .836 & & \\
\hline $\mathrm{OW} \rightarrow \mathrm{OW} 4$ & .819 & & \\
\hline $\mathrm{OW} \rightarrow$ OW5 & .830 & & \\
\hline Location (LO) & & .577 & .841 \\
\hline $\mathrm{LO} \rightarrow \mathrm{LO} 1$ & .834 & & \\
\hline $\mathrm{LO} \rightarrow \mathrm{LO} 2$ & .911 & & \\
\hline $\mathrm{LO} \rightarrow \mathrm{LO} 3$ & .579 & & \\
\hline $\mathrm{LO} \rightarrow \mathrm{LO} 4$ & .670 & & \\
\hline Agency (AG) & & .519 & .810 \\
\hline $\mathrm{AG} \rightarrow \mathrm{AG} 1$ & .667 & & \\
\hline $\mathrm{AG} \rightarrow \mathrm{AG} 2$ & .834 & & \\
\hline $\mathrm{AG} \rightarrow \mathrm{AG} 3$ & .615 & & \\
\hline $\mathrm{AG} \rightarrow \mathrm{AG} 4$ & .747 & & \\
\hline Enjoyment (EN) & & .673 & .859 \\
\hline $\mathrm{EN} \rightarrow \mathrm{EN} 1$ & .877 & & \\
\hline $\mathrm{EN} \rightarrow \mathrm{EN} 2$ & .694 & & \\
\hline $\mathrm{EN} \rightarrow \mathrm{EN} 3$ & .876 & & \\
\hline Experience (EX) & & .793 & .920 \\
\hline $\mathrm{EX} \rightarrow \mathrm{EX} 1$ & .901 & & \\
\hline $\mathrm{EX} \rightarrow \mathrm{EX} 2$ & .900 & & \\
\hline $\mathrm{EX} \rightarrow \mathrm{EX} 3$ & .870 & & \\
\hline
\end{tabular}


Table 4. Correlation Matrix and Square Roots of AVE

\begin{tabular}{lccccc}
\hline & OW & LO & AG & EN & EX \\
\hline Ownership (OW) & $\mathbf{0 . 7 7 8}$ & & & & \\
Location (LO) & 0.633 & $\mathbf{0 . 7 6 0}$ & & & \\
Agency (AG) & 0.584 & 0.478 & $\mathbf{0 . 7 2 0}$ & & \\
Enjoyment (EN) & 0.592 & 0.484 & 0.447 & $\mathbf{0 . 8 2 0}$ & \\
Experience (EX) & 0.541 & 0.443 & 0.408 & 0.646 & $\mathbf{. 8 9 0}$ \\
\hline AVE $=$ average variance extracted & & & & &
\end{tabular}

Table 5. Hypothesis Testing

\begin{tabular}{ccccc}
\hline Hypotheses & Paths & Estimates & $\boldsymbol{p}$-Values & Support for Hypotheses \\
\hline H1a & EM $\rightarrow$ OW & 0.880 & .00 & Supported \\
H1b & EM $\rightarrow$ LO & 0.720 & .00 & Supported \\
H1c & EM $\rightarrow$ AG & 0.664 & .00 & Supported \\
H2 & EM $\rightarrow$ EN & 0.673 & .00 & Supported \\
H3 & EM $\rightarrow$ EX & 0.330 & .00 & Supported \\
H4 & EN $\rightarrow$ EX & 0.424 & .00 & Supported \\
\hline
\end{tabular}

Table 6. The Satorra-Bentler Scaled Chi-Square Difference Test

\begin{tabular}{lccccc}
\hline \multicolumn{1}{c}{ Models } & $\begin{array}{c}\text { Satorra-Bentler } \\
\text { Adjusted } \chi^{2}\end{array}$ & $\boldsymbol{d f}$ & $\begin{array}{c}\text { Scaling Correction } \\
\text { Factor }\end{array}$ & $\begin{array}{c}\boldsymbol{T} \\
(\boldsymbol{d} \boldsymbol{f}=\mathbf{1})\end{array}$ & $\boldsymbol{p}$ \\
\hline Model 2 (Null) & 296.251 & 147 & 1.1731 & & \\
Model 1 (Alternative) & 283.113 & 146 & 1.1728 & 12.735 & .000 \\
& & & & & \\
Model 3 (Null) & 291.181 & 147 & 1.1752 & & \\
Model 1 (Alternative) & 283.113 & 146 & 1.1728 & 6.660 & .010 \\
\hline
\end{tabular}


Figure 1. The Structural Model of Technology Embodiment

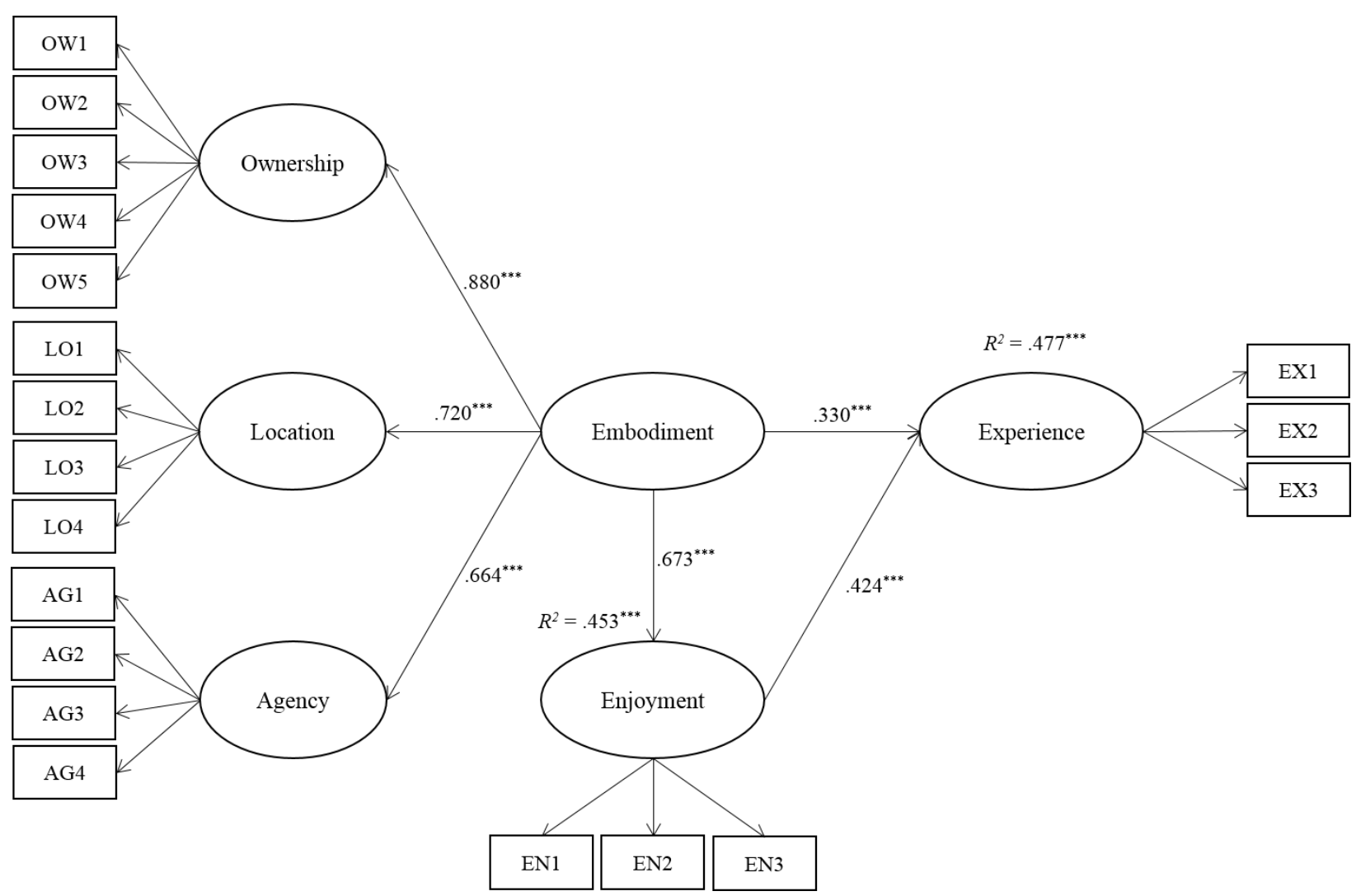

Indices: Akaike Information Criterion $(\mathrm{AIC})=10619.981$; Bayesian Information Criterion $(\mathrm{BIC})=10826.180 ; \chi^{2}=$ 283.113; $d f=146 ; p=.000 ;$ Comparative Fit Index $(\mathrm{CFI})=.928$; Tucker-Lewis Index $(\mathrm{TLI})=.915$; Root Mean Square Error of Approximation $(\mathrm{RMSEA})=.069 ;$ Standardized Root Mean Square Residual $(\mathrm{SRMR})=.065 ; N=$ 195. See Table 3 for item-to-construct estimates. 